\title{
Trastornos psiquiátricos primarios en dermatología
}

\author{
Primary psychiatric disorders in dermatology
}

\author{
John Fredy Ballén', Lizeth Milena Pinzón², Ángel Omar Jaimes³, Álvaro José Tovar \\ 1. Médico, residente de Dermatología, Fundación Universitaria Sanitas, Bogotá, D.C., Colombia \\ 2. Médica, residente de Psiquiatría, Fundación Universitaria Sanitas, Bogotá, D.C., Colombia \\ 3. Médico dermatólogo, Universidad CES, Centro Dermatológico Federico Lleras Acosta, Bogotá, Colombia \\ 4. Médico dermatólogo de planta, Centro Dermatológico Federico Lleras Acosta, Bogotá, Colombia.
}

\section{RESUMEN}

Los trastornos psiquiátricos primarios relevantes en el contexto de la dermatología, comprenden un grupo de enfermedades caracterizadas por una alteración mental, asociada a afecciones cutáneas secundarias y autoinducidas. Aunque la consulta dermatológica puede ser el primer contacto médico de estos pacientes, la gran mayoría requiere el apoyo integral de otras disciplinas como la psiquiatría. Es por esto que el uso de herramientas clave en el acto médico son esenciales para identificar el tipo de trastorno y generar empatía con el paciente, lo que permitirá un adecuado manejo y la aceptación de una futura remisión al psiquiatra, para evitar complicaciones graves como la perpetuación de la enfermedad y el suicidio, entre otras. En este trabajo se pretende dilucidar las principales características clínicas y el abordaje de estas complejas enfermedades.

PALABRAS CLAVE: conducta autodestructiva, delirio de parasitosis, trastorno dismórfico corporal, trastornos fingidos, tricotilomanía.

\section{SUMMARY}

The main primary psychiatric disorders in dermatology are a group of diseases characterized by a disturbance in the psyche, associated with secondary skin conditions and self-induced injury. Although the dermatologist may be the first physician in contact with these patients, support from other specialties such as psychiatry may be necessary. The acquisition of abilities in the medical act is essential to identify the type of disorder and to generate empathy, allowing proper management and acceptance of a possible referral to a psychiatrist. All this is very important to avoid serious complications such as the perpetuation of the disorder or even suicide. This work aims to elucidate the clinical features and management of these complex diseases

KEYWORDS: Body dysmorphic disorders, delusional parasitosis, factitious disorders, self-injurious behavior, trichotillomania.

\section{INTRODUCCIÓN}

La psicodermatología, o medicina psicocutánea, comprende un grupo de trastornos en los límites entre la psiquiatría y la dermatología. Este campo no es nuevo, pero frecuentemente ha recibido atención limitada, y solo en las últimas dos dé-

\author{
Correspondencia: \\ John Fredy Ballén \\ Email: \\ jjobaf@gmail.com \\ Recibido: 21 de septiembre de 2015 \\ Aceptado: 12 de febrero de 2016 \\ No se reportan conflictos de \\ interés.
}


cadas ha ganado popularidad y se ha incrementado su estudio por dermatólogos del mundo entero ${ }^{1,2}$. Se calcula que, aproximadamente, 30 a $40 \%$ de los pacientes que buscan tratamiento para alguna enfermedad cutánea, tienen un problema psicológico o psiquiátrico que puede causar o exacerbar un problema cutáneo. Existe amplia información en la literatura científica que sugiere que el curso de muchos trastornos cutáneos está afectado por el estrés u otros eventos psicológicos, y que las condiciones dermatológicas deformantes frecuentemente tienen un curso crónico, produciendo una morbilidad psicológica importante, lo cual lleva a un trastorno psiquiátrico secundario que afecta la calidad de vida de quienes lo padecen ${ }^{3,4}$.

El sistema nervioso y la piel tienen un origen embriológico común en la placa neural del ectodermo $0^{3,4,5}$, por lo que se ha intentado investigar en forma amplia la relación entre la mente y la piel. Se ha reportado que el estrés psicológico perturba la homeostasis de la permeabilidad de la barrera epidérmica y esto puede actuar como un factor precipitante para algunos trastornos inflamatorios, como la dermatitis atópica y la psoriasis, por lo que la relación entre mente y cuerpo tiene en la piel a uno de sus principales exponentes ${ }^{5}$.

El modelo neuro-inmuno-endrocrino-cutáneo fue propuesto por O’Sullivan, et al. ${ }^{6}$, e intenta explicar por qué muchas dermatosis cutáneas son desencadenadas o exacerbadas por factores psicológicos. Estos sistemas comparten un complejo lenguaje de neuropéptidos, citocinas, glucocorticoides y otras moléculas efectoras ${ }^{5}$. El eje hipotálamo-hipofisario reacciona al estrés psicológico aumentando la producción y la liberación de las hormonas del estrés (hormona liberadora de corticotropina, hormona liberadora de adrenocorticotropina y prolactina) activando el sistema nervioso simpático, elevando los niveles de catecolaminas y facilitando la liberación de neuropéptidos y neuromediadores (sustancia $\mathrm{P}$ y péptido relacionado con el gen de la calcitonina).

Los mastocitos cutáneos son un blanco importante de las hormonas del estrés y de los mediadores; su activación lleva a una desregulación inmunitaria y a varios trastornos cutáneos ${ }^{7}$. Arck, et al., sugieren que la piel está exquisitamente bien inervada y tiene su propio sistema neuroendocrino, equivalente al eje hipotálamo-hipofisario, el cual está vinculado al sistema neuroendocrino principal ${ }^{8}$.

Los pacientes con trastornos psicocutáneos frecuentemente se resisten a una remisión al psiquiatra, por lo que se requiere una aproximación biopsicosocial desde la atención primaria, asistiendo las necesidades médicas y afectivas de los pacientes con enfermedades psicocutáneas 5 , y una aproximación multidisciplinaria con la cooperación de psiquiatría y dermatología, para ofrecer un tratamiento integral en este tipo de $\operatorname{casos}^{3,4}$.

\section{CLASIFICACIÓN DE LOS TRASTORNOS PSICOCUTÁNEOS}

Aunque no hay un sistema de clasificación universalmente aceptado de los trastornos psicocutáneos, el más utilizado se divide en tres categorías de acuerdo con la relación entre las enfermedades cutáneas y los trastornos mentales, en:

I. Trastornos psicofisiológicos (psicosomáticos) causados por enfermedades cutáneas activadas por diferentes estados emocionales (estrés), pero no directamente relacionadas con trastornos mentales.

II. Trastornos psiquiátricos primarios responsables de trastornos cutáneos autoinducidos.

III. Trastornos psiquiátricos secundarios causados por una piel desfigurada, que puede llevar a estados de ansiedad, depresión o ideación suicida $^{3,4,9,10}$

En la TABLA 1 se resume la clasificación de las principales psicodermatosis y en esta revisión profundizaremos en los trastornos psiquiátricos primarios con mayor relevancia en dermatología.

\section{TRASTORNOS PSIQUIÁTRICOS PRIMARIOS}

Estas enfermedades han recibido poco énfasis en la literatura psiquiátrica o dermatológica, a pesar de que pueden estar asociadas con el suicidio y con la práctica de procedimientos quirúrgicos innecesarios ${ }^{3}$.

Durante los últimos cinco años, en el Centro Dermatológico Federico Lleras Acosta, se llevaron a cabo 464 consultas relacionadas con alguno de estos trastornos $^{11}$. Muchos de estas enfermedades ocurren en el contexto de un trastorno delirante, somatomorfo, del control de los impulsos, de la personalidad, de la alimentación, de la ansiedad o de la depresión. El dermatólogo desempeña un papel importante en estos casos, inicialmente sospechando y luego estableciendo el diagnóstico para proporcionar un manejo adecuado. Algunos diagnósticos son fáciles y sencillos, pero, muchas de estas enfermedades pueden simular otros trastornos cutáneos, por lo que se requiere un alto grado de sospecha para llegar a un diagnóstico correcto ${ }^{4}$. 


\begin{tabular}{|c|c|c|}
\hline Trastornos psicofisiológicos & $\begin{array}{l}\text { Dermatitis atópica } \\
\text { Infección por herpes simple } \\
\text { Hiperhidrosis } \\
\text { Efluvio telógeno } \\
\text { Dermatitis seborreica } \\
\text { Acné } \\
\text { Alopecia areata } \\
\text { Rosácea } \\
\text { Vitíligo } \\
\text { Urticaria }\end{array}$ & \\
\hline \multirow{7}{*}{$\begin{array}{l}\text { Trastornos psiquiátricos } \\
\text { primarios }\end{array}$} & Trastorno por creencias dermatológicas & Delirio de infestación \\
\hline & Trastornos del control de impulsos & $\begin{array}{l}\text { Trastorno dismórfico corporal, } \\
\text { tricotilomanía, tricoteiromanía, } \\
\text { tricotemnomanía, onicofagia, } \\
\text { onicotilomanía, onicotemnomanía, } \\
\text { morsicatio bucarum, queilitis } \\
\text { facticia, pseudoalmohadillas en los } \\
\text { nudillos, excoriaciones neuróticas, } \\
\text { acné excoriado }\end{array}$ \\
\hline & Enfermedades cutáneas facticias & $\begin{array}{l}\text { Dermatitis artefacta, dermatitis } \\
\text { paraartefacta, trastorno por } \\
\text { simulación, dermatitis simulata, } \\
\text { dermatosis neglecta }\end{array}$ \\
\hline & Formas especiales & $\begin{array}{l}\text { Síndrome de Gardner-Diamond, } \\
\text { síndrome de Münchausen y } \\
\text { síndrome de Münchausen por } \\
\text { poder }\end{array}$ \\
\hline & \multicolumn{2}{|l|}{ Prurito psicógeno } \\
\hline & Fobias cutáneas & $\begin{array}{l}\text { Fobia a los lunares, venerofobia, } \\
\text { fobia a las verrugas }\end{array}$ \\
\hline & Trastornos sensoriales cutáneos & $\begin{array}{l}\text { Glosodinia, vulvodinia, } \\
\text { escrotodinia, anodinia }\end{array}$ \\
\hline $\begin{array}{l}\text { Entidades dermatológicas } \\
\text { que pueden desencadenar } \\
\text { trastornos psiquiátricos } \\
\text { secundarios }\end{array}$ & $\begin{array}{l}\text { Acné } \\
\text { Alopecias } \\
\text { Psoriasis } \\
\text { Vitiligo } \\
\text { Neoplasias cutáneas } \\
\text { Trastornos de la pigmentación }\end{array}$ & \\
\hline
\end{tabular}

TABLA 1. Clasificación de las principales psicodermatosis.

\section{TRASTORNO POR CREENCIAS DERMATOLÓGICAS}

\section{Delirio de infestación}

Es una condición en la cual el paciente tiene una idea falsa y fija de estar infestado por pequeños patógenos vivos o inanimados, sin que haya una evidencia médica objetiva de esto. Por definición, los pacientes desconocen el origen psiquiátrico de la enfermedad y con- secuentemente rechazan las remisiones al psiquiatra o las medicaciones antipsicóticas ${ }^{12-16}$.

En 1938, el neurólogo sueco Karl Axel Ekbom fue el primero en diferenciar esta condición patológica de un simple temor a los insectos y lo llamó con el término alemán Dermatozoenwahn; por su difícil pronunciación, en muchos países se empezó a conocer con el epónimo de "síndrome de Ekbom" que, aunque se usa en la actualidad, es ambiguo y no se recomienda porque también sirve para describir el síndrome de las piernas inquietas. 
FIGURA 1. Úlceras y excoriaciones autoinducidas en una paciente que creía estar infestada por "gusanos"

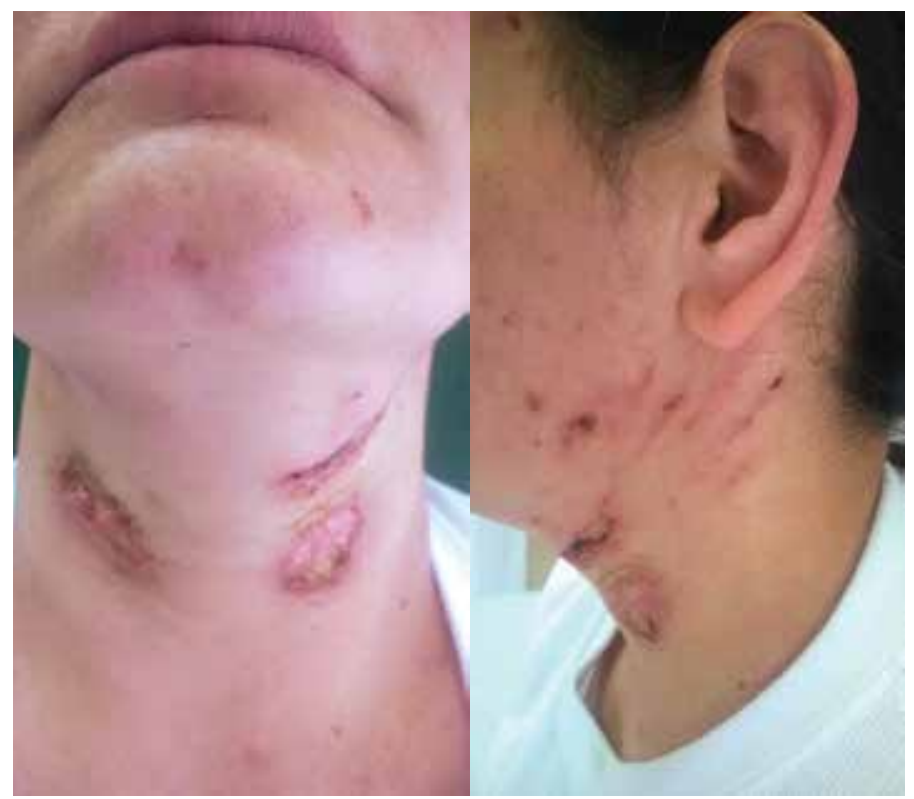

En 1946, Wilson y Miller acuñaron el término actual y más aceptado: delirio de parasitosis. No obstante, en los últimos años los pacientes han reportado múltiples tipos de patógenos diferentes a los parásitos, por lo que en el 2009, Freudenmann, et al., propusieron el nombre de delirio de infestación ${ }^{1,12,17,18}$.

El síndrome Morgellons es una condición controversial, que consiste en la creencia de infestación por fibras e hilos en la piel, el cual causa síntomas neuropsiquiátricos inespecíficos y problemas cutáneos, que frecuentemente se reportan en portales web y redes sociales. Aunque en la comunidad dermatológica esta condición ha sido reconocida como sinónimo de un delirio de infestación ${ }^{13}$, muchos consideran que se trata de un fenómeno de masas, "cibercondría”, es decir, una enfermedad transmitida socialmente por internet ${ }^{19,20}$.

Según el metaanálisis de Trabert, la prevalencia del delirio de infestación es de 5,58 casos por 1 millón de personas en los servicios públicos y asciende hasta 83,23 por 1 millón en la práctica privada ${ }^{21}$. Existe una distribución bimodal por edad, con un pico de prevalencia entre los 20 y 30 años de edad, y otro en mayores de 50 años ${ }^{13}$.

En su revisión de 2009, Freudenmann y Lepping sintetizaron los criterios diagnósticos para el delirio de infestación en:
- Existe la convicción de estar infestado por un patógeno animado o inanimado, sin una evidencia médica o microbiológica de una verdadera infestación.

- El paciente presenta una sensación cutánea anormal explicada por el primer criterio ${ }^{12}$.

El delirio de infestación puede presentarse como una psicosis primaria o secundaria. Los pacientes con psicosis primaria (o psicosis monosintomática hipocondríaca) experimentan sensaciones cutáneas como animales que caminan, muerden o pican, generando ardor y prurito ${ }^{13}$. El delirio de infestación primario debe distinguirse del 'hormigueo' (formication), en el cual el paciente tiene sensaciones similares sobre su piel, sin que exista un delirio, es decir, no hay una idea fija de que estos síntomas sean causados por parásitos $\mathrm{u}$ otros patógenos y se acepta fácilmente la evidencia de no tener una infestación ${ }^{16}$. Por otro lado, en la psicosis secundaria, la etiología puede ser una condición médica de base (por ejemplo, neurológica o psiquiátrica), el consumo de medicamentos o el uso de sustancias ilícitas ${ }^{13-15}$.

Es frecuente encontrar una historia de múltiples consultas a medicina general y dermatología, tratando de buscar una solución ${ }^{12}$. El inicio y el progreso 
del delirio de infestación suelen ser insidiosos ${ }^{22}$; su comienzo agudo debe alertar sobre la presencia de una intoxicación aguda, un delirio o un déficit neurológico. Los pacientes frecuentemente elaboran una historia de cómo los diferentes patógenos se reproducen, mueven y diseminan bajo la piel ${ }^{3}$.

Un patrón interesante es el tamaño presumido del patógeno, por lo general, se describen como muy pequeños para ser vistos o diminutos, por lo que es difícil recolectarlos. Los patógenos que son más grandes, de centímetros, no son característicos de un delirio de infestación primario y más bien indican psicosis tóxica, delirio o esquizofrenia.

Por lo general, los pacientes intentan varias técnicas para deshacerse de la infestación, como el uso de pesticidas en ellos mismos, en sus mascotas o en sus hogares. Puede haber cambios importantes en los hábitos, al hacer varios esfuerzos para librarse de los parásitos, como mudarse de la vivienda o aislarse de amigos y familiares, por miedo de contaminar a otras personas.

Los pacientes se autoexaminan frecuentemente, creando rituales gradualmente más elaborados y autodestructivos, que cada vez toman más tiempo durante el día, con el uso de instrumentos como lupas, pinzas, espejos, exfoliantes o cortaúñas, intentando remover los patógenos de la piel y causándose excoriaciones (FIGURA 1), úlceras, erosiones, pérdida del cabello, liquen simple crónico, prurigo nodular e infecciones secundarias ${ }^{12}$.

Alrededor de 25 a $75 \%$ de los pacientes con delirio de infestación traerán especímenes a la consulta médica, para probar la existencia de la infestación; esto se conoce como el "signo del espécimen". Usualmente, estas muestras están compuestas de restos cutáneos, escamas, costras o cabello; ocasionalmente, pueden consistir en filamentos textiles, pelusa, material vegetal, insectos o sus partes, no relacionados con el tipo de lesión cutánea ${ }^{12,13}$.

Las localizaciones más frecuentes de las lesiones son en la piel de los miembros superiores e inferiores, el cuero cabelludo, el tronco superior, los genitales y los orificios corporales, como nariz, oídos, boca y ano; la afectación de todo el cuerpo es rara. Las lesiones usualmente son más graves en el lado opuesto al de la mano dominante ${ }^{13}$.

Cuando este tipo de delirio es compartido por otra persona, usualmente la pareja, recibe el nombre de folie a deux ("locura para dos") ${ }^{16,17}$; se considera que de 8 a $12 \%$ de los pacientes tienen un amigo o familiar que comparte los mismos síntomas. Por otro lado, el delirio de infestación por proximidad, consiste en un cuadro caracterizado por la creencia de que el compañero, los hijos, otras personas o las mascotas están infestadas, pero no el paciente con la condición real ${ }^{12}$.

La posibilidad de una verdadera infestación (por ejemplo, escabiosis incógnita), así como la presencia de causas psiquiátricas o médicas que contribuyan a una psicosis, deben tenerse presentes entre los diagnósticos diferenciales. El practicar una biopsia no cambia la impresión clínica del diagnóstico ni el pronóstico ${ }^{23}$.

En general, los dermatólogos tienen la impresión de que estos pacientes padecen una grave alteración mental que tiende a la cronicidad y es de mal pronóstico. Sin embargo, hay que destacar que la gama de pacientes con delirio de infestación es muy amplia y muchos de los casos pueden evolucionar favorablemente, por lo que deben ser valorados y tratados a la mayor brevedad posible ${ }^{24}$.

De acuerdo con el esquema de tratamiento de Heller, et al. ${ }^{13}$, existen dos aspectos generales para un óptimo manejo del delirio de infestación, que se resumen en desarrollar una aproximación interpersonal constructiva con el paciente e instaurar un manejo farmacológico adecuado.

Aprender cómo interactuar con un paciente con delirio de infestación puede ser más útil que aprender a prescribir un medicamento. El médico tratante debe construir y mantener una alianza confiable con el paciente, para realizar un diagnóstico correcto y una prescripción efectiva. Se debe tener en mente que el objetivo de la consulta es mejorar la condición del paciente y, no, convencerlo de que está padeciendo un delirio. Debe aclararse explícitamente que el médico no está en condiciones para encontrar el agente patógeno, pero que será capaz de mejorar los síntomas si trabajan conjuntamente y que debe confiar en su experiencia al tratar previamente casos similares. Gentilmente se debe comunicar que centrarse en conocer la etiología exacta de la condición no es fructífero ${ }^{13}$.

Es necesario analizar las muestras que trae el paciente; esta es una técnica fácil y poderosa para comunicar respeto por sus preocupaciones y bienestar. La dermatoscopia es una nueva y práctica ayuda para examinar los artefactos presentados ${ }^{25}$. Se debe hacer un examen físico corporal completo, lo que ayuda a generar confianza y descartar otras condiciones dermatológicas.

Es frecuente encontrar casos con dermatitis de contacto e infecciones secundarias que requieren manejo. Hay que considerar el uso de antihistamínicos para mejorar el prurito, suspender medicaciones que induzcan prurito y evitar el aislamiento social tanto como sea posible ${ }^{12}$.

La remisión a psiquiatría debe hacerse cuando se 


\begin{tabular}{|c|c|c|c|c|}
\hline Principio activo & Dosis de inicio & $\begin{array}{l}\text { Dosis } \\
\text { terapéutica }\end{array}$ & Efectos secundarios & Consideraciones generales \\
\hline \multicolumn{5}{|c|}{ ANTIPSICÓTICOS TÍPICOS (PRIMERA GENERACIÓN) } \\
\hline $\begin{array}{l}\text { Pimozida } \\
\text { (no se encuentra } \\
\text { disponible en } \\
\text { Colombia) }\end{array}$ & $0,5 \mathrm{mg} / \mathrm{día}$ & $2-3 \mathrm{mg} / \mathrm{dí}$ & $\begin{array}{l}\text { Sedación, prolongación del QT, } \\
\text { efectos extrapiramidales que } \\
\text { pueden ser permanentes }\end{array}$ & $\begin{array}{l}\text { Contraindicado con el uso } \\
\text { concurrente de antidepresivos, } \\
\text { macrólidos, fluoroquinolonas } \\
\text { o azoles. Se requiere } \\
\text { electrocardiograma antes y } \\
\text { durante el tratamiento. }\end{array}$ \\
\hline Haloperidol & $0,5 \mathrm{mg} /$ noche & $\begin{array}{l}1-5 \mathrm{mg} / \\
\text { noche }\end{array}$ & $\begin{array}{l}\text { Disquinesia tardía, síndrome } \\
\text { neuroléptico maligno }\end{array}$ & \\
\hline \multicolumn{5}{|c|}{ ANTIPSICÓTICOS ATÍPICOS (SEGUNDA GENERACIÓN) } \\
\hline Risperidona & $1 \mathrm{mg} /$ noche & 3-5 mg día & $\begin{array}{l}\text { Mareo, ansiedad, rinitis, } \\
\text { aumento del apetito, aumento de } \\
\text { peso, hiperprolactinemia } \\
\text { Prolongación del QT }\end{array}$ & $\begin{array}{l}\text { Vigilar niveles de prolactina } \\
\text { Primera línea para el delirio } \\
\text { de infestación para algunos } \\
\text { autores. } \\
\text { Por los efectos anticolinérgicos } \\
\text { limitados, puede formularse } \\
\text { en ancianos. }\end{array}$ \\
\hline Olanzapina & 5-10 mg/día & 10-15 mg/día & $\begin{array}{l}\text { Síndrome metabólico, aumento } \\
\text { de peso, efectos anticolinérgicos }\end{array}$ & $\begin{array}{l}\text { Vigilar aumento de peso, } \\
\text { glucemia en ayunas, } \mathrm{HbA}_{1} \mathrm{C} \text { y } \\
\text { niveles de lípidos }\end{array}$ \\
\hline Quetiapina & $12,5 \mathrm{mg} /$ noche & $\begin{array}{l}150 \text { a } 600 \\
\mathrm{mg} / \text { noche }\end{array}$ & $\begin{array}{l}\text { Somnolencia que usualmente } \\
\text { mejora en } 3 \text { a } 7 \text { días, moderada } \\
\text { ganancia de peso Hipotensión } \\
\text { ortostática, mayor riesgo de } \\
\text { caídas }\end{array}$ & $\begin{array}{l}\text { Útil en ancianos } \\
\text { Por lo general, se toleran } \\
\text { mejor los efectos adversos } \\
\text { que con otros antipsicóticos } \\
\text { (indicación no aprobada por } \\
\text { la FDA) }\end{array}$ \\
\hline
\end{tabular}

TABLA 2. Antipsicóticos de elección para el tratamiento del delirio de infestación.

haya logrado la compenetración con el paciente, haciéndole saber que se hace, no porque se crea que su condición sea de causa imaginaria, sino porque el médico tratante sabe el sufrimiento que la enfermedad le ha ocasionado en su vida y quizá requiera de un especialista con mayor entrenamiento en este campo para poder ayudarlo.

No debe haber presión para iniciar los antipsicóticos en las primeras visitas y se recomienda que se formulen solo si hay certeza en el diagnóstico; se deben conocer las indicaciones y efectos adversos de los medicamentos para hacer un seguimiento adecuado. Cuando se escoja un tratamiento, es importante determinar si el paciente sufre de una psicosis primaria o secundaria. En el primer caso, prescribir una medicación antipsicótica es la intervención más eficaz que el médico tratante puede ofrecer, mientras que, en los delirios secundarios, es necesario tratar la condición de base.

Las opciones de tratamiento para el delirio de infestación primario incluyen antipsicóticos de primera (típicos) y de segunda generación (atípicos) ${ }^{22}$. Los tí- picos (pimozida, haloperidol) tienen mayor y fuerte afinidad por el receptor de la dopamina, lo cual aumenta el riesgo de extrapiramidalismo. Por otro lado, los antipsicóticos atípicos (risperidona, olanzapina, quetiapina) producen un bloqueo de mayor afinidad por el receptor de la serotonina que por el de la dopamina, y mayor selectividad por los receptores relacionados con los síntomas psicóticos, lo cual disminuye el riesgo de extrapiramidalismo ${ }^{13,26}$.

En todos los casos, antes de iniciar el tratamiento, se recomienda practicar un electrocardiograma por el riesgo de arritmias, y un hemograma, con control al mes y a los seis meses, con el objetivo de identificar los signos que sugieran supresión medular, como leucopenia, neutropenia y agranulocitosis.

Por el riesgo de efectos secundarios, los medicamentos deben iniciarse a dosis bajas e ir incrementándose paulatinamente cada dos semanas, según el perfil de efectos adversos que presente el paciente (TABLA 2). Si se llegasen a presentar, los síntomas extrapiramidales pueden ser tratados con 25 a $50 \mathrm{mg}$ de difenhidra- 
mina cada cuatro a seis horas. En los casos de delirio de infestación secundario, se debe hacer una investigación sobre la condición primaria (esquizofrenia, depresión, intoxicación crónica, enfermedades neurológicas $\mathrm{u}$ otras condiciones médicas), para dirigir un manejo multidisciplinario junto con otros especialistas (psiquiatras, neurólogos, toxicólogos, internistas, etc.) y lograr un tratamiento oportuno e integral.

Los retos del tratamiento para el delirio de infestación son bien conocidos, ya que es difícil garantizar su adecuado cumplimiento. Por esta razón, es importante comunicar al paciente el uso correcto de las dosis, advertir que los fármacos pueden tardar de seis a ocho semanas para obtener resultados terapéuticos óptimos y alertar sobre los probables efectos adversos. Una vez el paciente notifique alguna mejoría en los síntomas, estará animado a continuar el tratamiento, disminuirá la preocupación por encontrar la etiología y el médico tratante podrá mantener la dosis estable por al menos tres meses para, entonces, disminuirla paulatinamente hasta su suspensión, según la evolución ${ }^{13,15}$.

\section{TRASTORNOS DEL CONTROL DE IMPULSOS}

\section{Trastorno dismórfico corporal}

La imagen cutánea corporal se define como la percepción mental del individuo sobre la apariencia de su tegumento (piel, cabello y uñas) y es, quizá, uno de los principales constructos dermatológicos más frecuentemente distorsionados en el trastorno dismórfico corporal ${ }^{27,28}$.

Entre los pacientes que asisten a consulta de dermatología o cirugía plástica, de 6 a $15 \%$ padecen de trastorno dismórfico corporal en diferentes grados con importantes implicaciones ya que, si no se identifica, puede perturbar significativamente la satisfacción del paciente y afectar directamente los esquemas terapéuticos ofrecidos ${ }^{27}$.

La mayoría de las veces, el trastorno dismórfico corporal comienza temprano en la adolescencia, asociado con abusos (bullying) y está relacionado con una alta tasa de ideación suicida e intentos de suicidio, especialmente en este grupo etario ${ }^{27}$. Usualmente, son personas solteras, separadas, desempleadas o con antecedentes de abuso del alcohol u otras sustancias ilícitas ${ }^{3,28}$.

La etiología del trastorno dismórfico corporal es multifactorial e incluye factores biológicos, psicológicos y socioculturales. Los estudios neurofisiológicos y de neuroimágenes sugieren que puede haber anormalidades en el procesamiento visual y alteraciones de los circuitos fronto-estriales y temporo-parietooccipitales, que pueden estar asociados con los síntomas de pensamientos obsesivos y comportamientos compulsivos. Por otro lado, el trastorno dismórfico corporal y los rasgos obsesivo-compulsivos comparten una base genética, con una correlación de fenotipos en cerca de $65 \%$ de los $\operatorname{casos}^{28}$.

La enfermedad se caracteriza por una preocupación por defectos percibidos en la apariencia física, que son muy leves o incluso imperceptibles por otras personas, asociados a la presencia de comportamientos repetitivos (como mirarse en el espejo, asearse en exceso, camuflar las lesiones, rascarse la piel o querer asegurarse de las cosas) o actos mentales repetitivos (como comparar los "defectos" con la contraparte o con otras personas) como reacción a la intranquilidad por el aspecto, lo cual genera un considerable deterioro so$\mathrm{cial}^{29}$. Con frecuencia, los pacientes sienten que otras personas notan y comentan su supuesta deformidad y la culpan de todas sus dificultades en la vida; por lo general, no se sienten comprendidos y son reservados respecto a sus síntomas, por miedo a ser juzgados como vanidosos o narcisistas.

Los pacientes con esta condición son muy ricos en síntomas, pero pobres en signos de enfermedad orgánica $^{3}$. Las preocupaciones pueden centrarse en una o más áreas corporales; las más frecuentes ocurren en la piel (acné, cicatrices, líneas de expresión, arrugas, palidez, enrojecimiento, dilatación de los poros, trastornos pigmentarios, protuberancias o depresiones de ciertas áreas), el cabello (adelgazamiento o pérdida del cabello, excesivo vello corporal o facial), la nariz (tamaño o forma) o los genitales (tamaño, forma).

Por lo general, las mujeres tienen mayor probabilidad de preocuparse por la apariencia de la cara, las mamas, la nariz o el abdomen y por su peso; los hombres, por la constitución corporal, los genitales y el cabello. Típicamente, son "compradores médicos" que repetitivamente se someten a múltiples procedimientos y tratamientos como cirugías cosméticas, aplicación de toxina botulínica, inyección de rellenos o terapias con láser, para encontrar solución a sus defectos, pero la mayoría de las veces no están satisfechos con los resultados ${ }^{4}$. Los trastornos mentales concomitantes más frecuentes incluyen depresión, fobias sociales, trastornos de la alimentación y trastornos de la personalidad ${ }^{4}$. No obstante, por lo general no se llega a un diagnóstico formal por un profesional de la salud mental, hasta los 10 a 15 años de iniciado el cuadro clínico ${ }^{28}$.

En el DSM-5 (Diagnostic and Statistical Manual of Mental Disorders, fifth edition) se clasifica bajo los trastornos obsesivos compulsivos y relacionados, y sub- 
clasificado, dependiendo del grado de introspección sobre las creencias, en: "con introspección buena o aceptable”, "con poca introspección” o "con ausencia de introspección/con creencias delirantes”; este último puede ocurrir entre el 27 y el $39 \%$ de los casos y es de difícil manejo ${ }^{28,29}$.

El manejo es extremadamente difícil, porque los intentos para explicar la naturaleza trivial de las preocupaciones pueden ser inútiles. El mayor reto del médico tratante es cambiar la percepción del paciente, de su condición como una enfermedad dermatológica o estética, a la de una que requiere tratamiento psiquiátrico. Obviamente, esto dependerá de la introspección del paciente y en los casos de delirio, requerirá manejo como un trastorno psicótico 4 .

Por lo general, los intentos para corregir el defecto percibido, médica o quirúrgicamente, resultan inútiles. La literatura científica reporta dos tratamientos efectivos para el trastorno dismórfico corporal, que incluyen los inhibidores selectivos de la recaptación de serotonina y la terapia cognitivo-conductual, encontrándose mejores resultados cuando se combinan.

En el primer caso, los inhibidores selectivos de la recaptación de serotonina se consideran la primera línea de tratamiento. Sin embargo, estos pacientes requieren dosis más elevadas que las necesarias para cuadros de depresión y pueden tomar más tiempo para mejorar; el tratamiento debe continuarse, por lo menos, seis meses a un año después de que se logre la reacción terapéutica ${ }^{26,30}$. En un metaanálisis se sugiere que la fluoxetina es segura y más efectiva que el placebo para los casos de trastorno dismórfico corporal y que, junto con la clorimipramina, disminuye la gravedad de los síntomas ${ }^{31}$.

Por otro lado, la terapia cognitivo-conductual es un tratamiento multifacético basado en el aprendizaje de principios; incluye determinar el pensamiento desadaptativo y los comportamientos que mantienen los síntomas del trastorno dismórfico corporal y que deterioran el funcionamiento, para encontrar las formas de cambiarlos ${ }^{28}$.

\section{Tricotilomanía}

Es un trastorno que se caracteriza por un comportamiento repetitivo de halar y arrancar el pelo ${ }^{32}$, lo cual genera su pérdida y causa un malestar clínicamente significativo, con deterioro social, laboral, escolar o en otras áreas importantes del funcionamiento ${ }^{29}$.

Aunque no existen estudios epidemiológicos grandes, se estima que puede llegar a afectar entre 1 y 3 $\%$ de escolares y 1 y $3,5 \%$ de los adolescentes ${ }^{33,34}$. En la población infantil son frecuentes los reportes y algunos autores han sugerido que en niños menores de cinco años se puede representar un subtipo de tricotilomanía que es menos crónico y de mejor pronóstico que en los casos de inicio más tardío ${ }^{35}$.

El deterioro emocional es prevalente y pueden encontrarse sentimientos de culpa, vergüenza o baja autoestima. Por lo general estos individuos provienen de familias disfuncionales, en las cuales los conflictos pueden incrementar los niveles de estrés, exacerbando los síntomas de la tricotilomanía, y creando un círculo vicioso. Las enfermedades psiquiátricas concomitantes en adultos, como los trastornos de ansiedad, trastornos del estado del ánimo, consumo de sustancias psicoactivas, trastornos de la alimentación y trastornos de la personalidad, son frecuentes ${ }^{33}$.

El cuadro clínico se caracteriza porque los individuos han tenido varios intentos repetidos de disminuir o dejar de arrancar el pelo ${ }^{29}$. Si bien la mayor afectación se presenta en el cuero cabelludo, las cejas y las pestañas ${ }^{36}$, todas las áreas corporales pilosas pueden estar afectadas, incluyendo la región púbica, los brazos, las piernas y las axilas, lo que puede generar complicaciones locales en el sitio de tracción, como irritación cutánea e infecciones ${ }^{33}$. Más de la mitad de los pacientes arrancan pelo de más de un sitio $^{34}$. Muchos individuos reportan jugar con el pelo arrancado (por ejemplo, frotándolo entre los labios) y, aproximadamente, 10 a $30 \%$ experimentan tricofagia (ingestión del pelo), lo cual genera un riesgo elevado de tricobezoar (masa de pelo en el intestino), que puede desencadenar serias complicaciones gastrointestinales y requerir manejo quirúrgico ${ }^{35,37,38}$.

En el examen físico, a pesar de la densidad normal del cabello, se encuentran diferentes longitudes, incluyendo terminaciones cónicas, que demuestran nuevo crecimiento y terminaciones despulidas con cabellos rotos y quebrados a la mitad, o aparecer como pequeños puntos negros en la superficie del cuero cabelludo. Típicamente, la región afectada tiene una forma inusual y la prueba de tracción es negativa ${ }^{36}$ (FIGURA 2).

La tricoscopia es una herramienta novedosa y útil que permite diferenciar la tricotilomanía de otros diagnósticos diferenciales. Los hallazgos tricoscópicos más característicos son: pelos rotos irregulares; signo "V", cuando dos pelos emergen de una misma apertura folicular y se rompen a la misma altura; pelo en llama, residuo de pelo proximal, el cual permanece unido al cuero cabelludo después de halar el pelo en anágeno; pelo polvoriento, solo se visualiza un resto espolvoreado donde existía un tallo piloso que fue dañado en su totalidad por manipulación mecánica; pelos enro- 


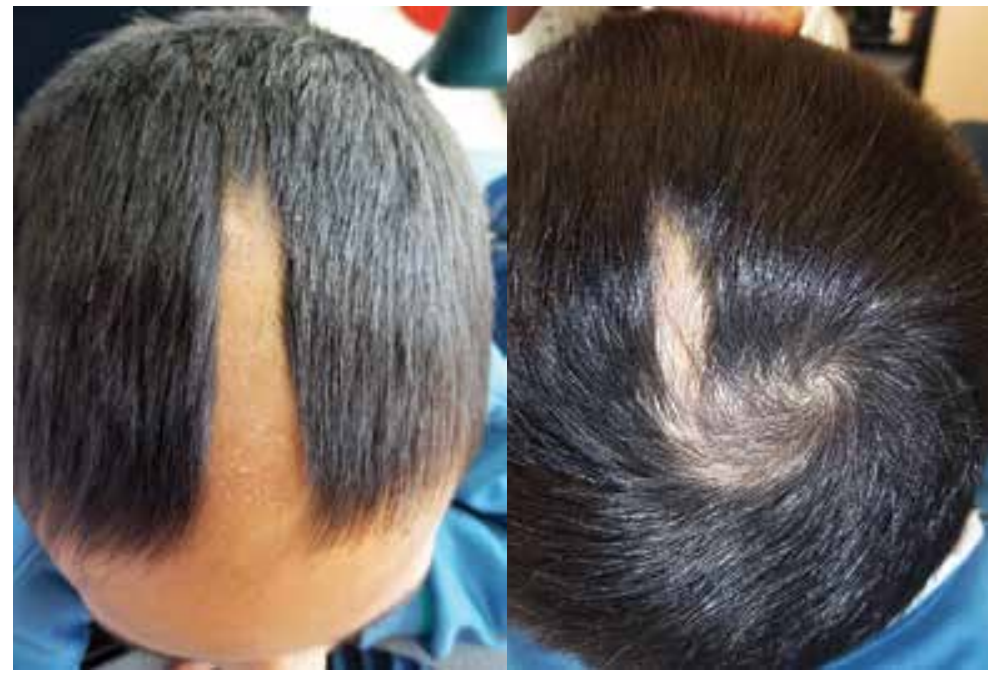

FIGURA 2. Tricotilomanía: áreas alopécicas secundarias a tracción compulsiva del pelo en un niño.

llados, como reacción a la fuerza de tracción, hay una fractura y la parte remanente distal se contrae y se enrolla; pelo en gancho o en signo de interrogación; y pelos en tulipán, terminaciones oscuras, en forma de la flor de tulipán, causados por una fractura diagonal ${ }^{39,40}$.

En los casos dudosos, la biopsia del sitio de la lesión puede ser de gran ayuda. Los signos histológicos de la tricotilomanía incluyen los folículos en anágeno vacíos, múltiples pelos en catágeno, incontinencia del pigmento melánico en el canal folicular y hemorragia peribulbar sin inflamación perifolicular. El signo más específico es la tricomalacia (bulbos pilosos con distorsión anatómica por el trauma y tallos pilosos enrollados), el cual puede producir formas interesantes como el "signo de la hamburguesa", en la cual hay una división orientada verticalmente en el tallo piloso, que contiene material proteico y eritrocitos; o la degeneración de la fibra pilosa puede tomar otras formas, como en el signo del 'perro caliente'38,41-43.

En el DSM-5, la tricotilomanía se clasifica dentro del espectro del trastorno obsesivo compulsivo y si bien varios estudios han demostrado que la tricotilomanía y este trastorno frecuentemente coexisten y aparecen en las mismas familias, existen importantes diferencias en su epidemiologia y fenomenología. Más importante aún, a diferencia de las compulsiones del trastorno obsesivo compulsivo, el comportamiento de arrancar el cabello en la tricotilomanía está asociado con sentimientos de placer y raramente, o nunca, es precedido por obsesiones patológicas o preocupaciones acerca de un daño potencial ${ }^{35,44}$. En su estudio, Rozeman, et al., sugieren que la tricotilomanía pediátrica es más parecida a un trastorno pediátrico de tics, que a un cuadro de trastorno obsesivo compulsivo, ansiedad o depresión ${ }^{45}$.

Los principales diagnósticos dermatológicos diferenciales incluyen la alopecia areata (que con alguna frecuencia puede coexistir con la tricotilomanía), en la cual las zonas desnudas del cuero cabelludo son suaves, el signo de la tracción es positivo y puede asociarse a cambios ungulares como la presencia de hoyuelos, a diferencia de la tricotilomanía, en la cual hay una sensación áspera al tacto y no hay cambios ungulares asociados. Otros diagnósticos que deben tenerse en mente, son la alopecia androgénica, la alopecia por tracción, la alopecia mucosa, el liquen plano pilaris, el lupus eritematoso discoide, la pseudopelada, la foliculitis decalvans y la sífilis ${ }^{36}$.

La tricotilomanía puede ser grave y extremadamente difícil de controlar. La hipótesis que en su etiología intervengan neurotransmisores como dopamina, glutamato o ácido gamma-aminobutírico, ha fomentado el uso de medicamentos estabilizadores del estado del ánimo, antipsicóticos y relacionados con la dopamina y la serotonina ${ }^{32}$. No obstante, en los últimos 25 años se han realizado varias investigaciones con la mayoría de estos medicamentos, sin que se haya establecido un esquema estándar, lo que refleja el poco entendimiento sobre la neurobiología de la tricotilomanía ${ }^{46}$. Más aún, en la última revisión sistemática al respecto se concluyó que ninguna clase de medicamento en particular demuestra eficacia en su tratamiento y que existe información preliminar que sugiere efectos te- 
rapéuticos con la clorimipramina, la $\mathrm{N}$-acetilcisteína y la olanzapina, con base en tres estudios individuales, pero con muestras muy pequeñas ${ }^{47}$.

En general, según la opinión de expertos, la primera línea de tratamiento para la tricotilomanía es la terapia cognitivo-conductual, específicamente, el entrenamiento de inversión del hábito ${ }^{33,35}$.

\section{Onicofagia}

Se refiere al hábito de morder o mascar las uñas, usualmente con su deglución. El constante traumatismo, con el acortamiento de la parte distal del plato ungular, puede dar lugar o desencadenar infecciones, sangrado y malformaciones. Es usual que se relacione con conflictos no resueltos o estrés, con mayor predilección durante la infancia y la adolescencia, y afecta hasta el 45 $\%$ de las personas jóvenes ${ }^{48,49}$.

\section{Morsicatio buccarum}

Son placas lineales blancas, hiperqueratósicas, en la mucosa oral, a lo largo de la línea de oclusión o en los labios, causadas por el hábito compulsivo de succionar o morder constante o excesivamente estas zonas ${ }^{48,49}$.

\section{Queilitis facticia}

Son lesiones eccematosas del labio, con predisposición a causar impétigo secundario, causadas por el daño acumulativo de la piel por el estrés mecánico (succionar o lamer los labios), donde la saliva actúa como un irritante y causa humedad excesiva. Usualmente, la automanipulación afecta áreas limitadas y demarcadas que se extienden más allá del bermellón de los labios ${ }^{48,49}$.

\section{Pseudoalmohadillas en los nudillos}

Son lesiones cutáneas, que semejan almohadillas ásperas y gruesas sobre las articulaciones de los dedos. Las verdaderas almohadillas en los nudillos solo se presentan en las genodermatosis, caracterizadas por tejido fibroso rico en células, pero en este caso, son causadas por el frote, el masaje, la succión o la masticación de estas zonas. Es frecuente que ocurra en pacientes con retardo mental y bulimia ${ }^{48,49}$.

\section{Excoriaciones neuróticas}

Las excoriaciones neuróticas, también conocidas como excoriaciones psicógenas, dermatotilomanía o trastorno de excoriación ${ }^{50}$, son lesiones autoinducidas, ocasionadas al pellizcar, frotar o rascar repetitivamente la piel, en el contexto de un paciente que no puede controlar estos impulsos 3,36 .

Los estudios sugieren que hay una incidencia de 2 a $5 \%$ en los pacientes dermatológicos, con una relación mujer a hombre de 3:1. La edad de inicio, en promedio, se reporta entre los 40 y 60 años. La ansiedad y la depresión son frecuentes y son más comunes en aquellos con una historia familiar de síntomas de excoriaciones neuróticas ${ }^{3,51}$.

Recientemente, la entidad fue incluida en el DSM-5, con una serie de criterios que pueden resumirse en: producción de lesiones cutáneas; intentos repetidos de disminuir o dejar de rascarse la piel; generación de malestar clínicamente significativo o deterioro en lo social, laboral u otras áreas importantes del funcionamiento; no se puede atribuir a los efectos fisiológicos de una sustancia (por ejemplo, cocaína) u otra afección médica (por ejemplo, escabiosis); no se explica mejor por los síntomas de otro trastorno mental ${ }^{29}$.

Las acciones para traumatizar la piel son episódicas y pueden ser desencadenadas por la ansiedad o el estrés, por una sensación focal de prurito, por una condición cutánea o por encontrarse una irregularidad en la piel al pasar la mano. Una vez comienza el rascado, hay una acumulación de tensión, la cual se alivia solo cuando se lesiona la piel. Por lo general, las lesiones son causadas por las uñas, pero también, puede haber una historia de uso de agujas, pinzas o cualquier instrumento de uso manual ${ }^{51}$.

Las zonas más afectadas se confinan a las áreas donde las manos alcanzan a llegar, especialmente en la cara extensora de los antebrazos, los hombros, la parte superior de la espalda, el pecho, los glúteos y la cara anterior de los muslos. Por lo general, el espacio interescapular está respetado, creando el característico “signo de la mariposa”. Morfológicamente, las lesiones pueden ser circulares, lineares, limpias o con costras, exulceradas o ulceradas; los márgenes de las lesiones más antiguas pueden estar engrosados por el rascado repetido. También, puede presentarse sobreinfección y formación de prurigo nodular. Es común que las lesiones se encuentren en diferentes fases de desarrollo (recientemente excoriadas, ulceradas, con costras, con componentes nodulares, cicatrices circulares o lineales bien demarcadas, con hiperpigmentación o hipopigmentación posinflamatoria) ${ }^{51}$.

Las excoriaciones neuróticas pueden deteriorar significativamente la calidad de vida de los pacientes. Existe un amplio espectro de comportamientos. Para algunos pacientes, puede ocurrir casi que automáticamente cuando la mente se ocupa en otras tareas (por ejemplo, 
cuando leen, ven televisión o manejan el carro); para otros, puede haber un ritual diario que ocurre en lugares privados por muchas horas al día. La culpa y la vergüenza usualmente acompañan a ese comportamiento, lo que lleva al paciente a esperar muchos años antes de buscar ayuda ${ }^{51}$.

Siempre se deben descartar los trastornos cutáneos primarios que pueden generar prurito, irregularidades en la superficie de la piel o trastornos sistémicos que puedan aumentar la atención en la piel, creando una sensación alterada. Con esto en mente, deben descartarse enfermedad hepática, enfermedad renal, disfunción tiroidea y linfomas ${ }^{51}$.

El tratamiento puede requerir una combinación de farmacoterapia y terapia comportamental, en orden, para modular el estrés o la ansiedad subyacente y extinguir el hábito compulsivo de traumatizar la piel. Varios antidepresivos, en particular los inhibidores selectivos de la recaptación de serotonina y la doxepina, la cual también tiene propiedades antipruriginosas y sedativas, se han usado para el tratamiento en adultos. Los estudios de farmacoterapia en niños son insuficientes; sin embargo, se han reportado éxitos en el tratamiento con fluoxetina en adolescentes ${ }^{52}$. No obstante, antes de que estos métodos puedan considerarse, el paciente debe estar dispuesto a aceptar la naturaleza psiquiátrica de la condición y ser capaz de identificar los factores desencadenantes que lo llevan a la excoriación. Respecto al manejo dermatológico, el control del prurito es esencial; las opciones incluyen antipruriginosos tópicos, como la pramoxina, lociones con mentol o fenol y base emoliente. Los antihistamínicos pueden ser de ayuda. Las compresas frías mejoran la hidratación y aceleran la remoción de costras, produciendo sensación de alivio en la piel. Los antibióticos tópicos, como la mupirocina, o los antibióticos sistémicos, deben reservarse para los casos de infección evidente ${ }^{36}$.

\section{Acné excoriado}

El acné excoriado es una variante de las excoriaciones neuróticas, que ocurre en pacientes con acné o con trastorno dismórfico corporal, quienes pellizcan lesiones reales o percibidas, generando la producción de excoriaciones y cicatrices de predominio facial. Es frecuente en mujeres, en promedio hacia los 30 años. Aunque muchos pacientes con la entidad admiten problemas de autoestima o una necesidad compulsiva de traumatizar la piel, la mayoría no parecen tener un proceso psicopatológico de base, aunque esto no excluye el impacto psicosocial sustancial del acné52. El trata- miento debe incluir esquemas agresivos para mejorar el acné y, por lo demás, debe enfocarse como en las excoriaciones neuróticas ${ }^{4}$.

\section{Enfermedades cutáneas facticias}

Los trastornos facticios afectan de 0,05 a 0,4\% de la población general. Se definen como comportamientos autoagresivos que directa o indirectamente causan daños clínicamente relevantes, no vinculados necesariamente con el suicidio ${ }^{48}$.

Según el DSM-5, el trastorno facticio aplicado a uno mismo, debe cumplir los siguientes criterios:

- Falsificación de signos o síntomas físicos o psicológicos, o inducción de lesión o enfermedad, asociada a un engaño identificado.

- $\quad$ El individuo se presenta a sí mismo frente a los demás como enfermo, incapacitado o lesionado;

- El comportamiento engañoso es evidente, incluso en ausencia de una recompensa externa obvia.

- El comportamiento no se explica mejor por otro trastorno mental, como el trastorno delirante $\mathrm{u}$ otro trastorno psicótico ${ }^{29}$.

\section{Dermatitis artefacta}

Es un trastorno en el que el paciente produce intencionalmente signos y síntomas destructivos en su piel, originados de un modo secreto y misterioso, negando $\mathrm{su}$ responsabilidad en su aparición, con el objetivo inconsciente de satisfacer una necesidad psicológica, habitualmente el deseo de ser tratado médicamente $\mathrm{e}^{51,53}$.

La condición es más frecuente en mujeres que en hombres, con una relación de 3:1; puede aparecer a cualquier edad, especialmente en adolescentes y adultos jóvenes ${ }^{54}$, alrededor de los 20 años, y frecuentemente aparece en presencia de estrés psicosocial grave o trauma, que puede ser fácilmente identificable. La localización múltiple es una característica femenina, mientras que la localización única se observa predominantemente en varones. Afecta con mayor frecuencia a personas con escaso nivel sociocultural y no es rara su conexión con el medio hospitalario, especialmente, con personal paramédico ${ }^{53}$.

Las lesiones pueden distinguirse de las dermatosis primarias por ciertos patrones, como la localización; son más frecuente en partes de fácil acceso del cuerpo, donde el paciente alcanza, y contralateral a la mano dominante ${ }^{54}$; habitualmente, las palmas, las plantas, la nariz, la boca, los pabellones auriculares, el cuero cabelludo y los genitales, están respetados ${ }^{53}$. Las formas de las lesiones son inusuales, con bordes agudos y 


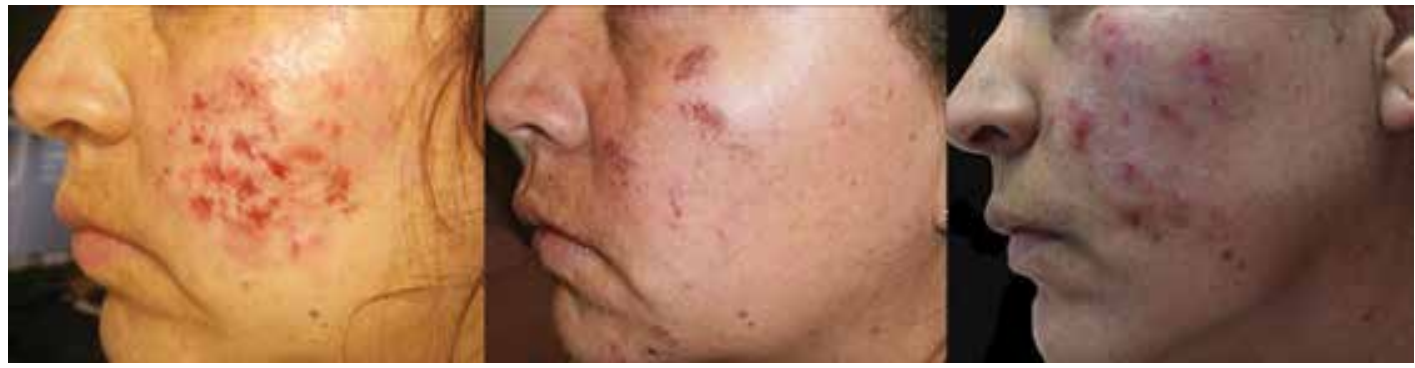

FIGURA 3. Dermatitis artefacta: múltiples excoriaciones en la mejilla de una misma paciente, en diferentes estadios y que no siguen el patrón de una dermatosis primaria.

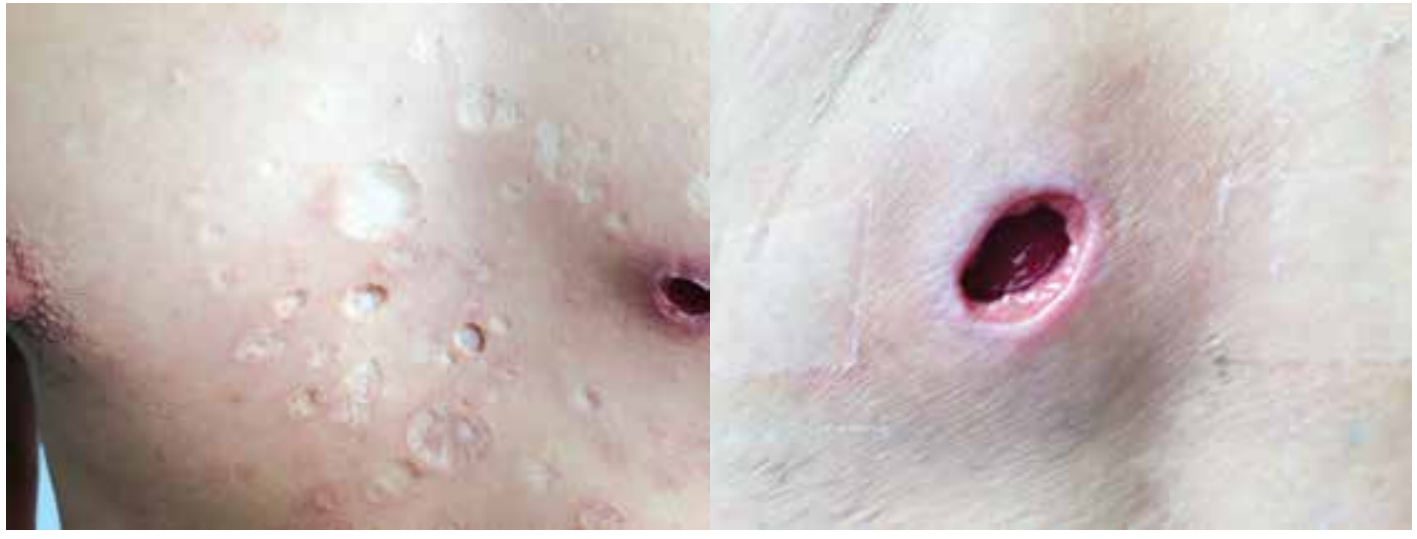

FIGURA 4. Dermatitis artefacta: cicatrices geométricas y úlcera con bordes netos autoinducidas (cortesía de la doctora Claudia Carvajal).

geométricos, márgenes perilesionales con piel sana y, en general, aspecto discordante con las lesiones cutáneas primarias. Existe una gran variedad de formas clínicas, que dependen del método empleado para causar la autolesión y de la creatividad del paciente.

Las más frecuentes son: las excoriaciones, de morfología lineal y en la mayoría de las ocasiones causadas con las uñas u objetos cortantes (FIGURA 3); las úlceras, con regularidad perfecta de los bordes o por el contrario, contornos irregulares con segmentos rectilíneos, ángulos agudos y obtusos (FIGURA 4); las ampollas, por fricción, quemaduras o cauterizaciones con agentes químicos o medicamentosos; la paniculitis, por inyección de sustancias o por traumatismos; las costras; las lesiones eccematosas (FIGURA 5); el edema, el linfedema recidivante unilateral, sin aparente obstrucción linfática o venosa, o bien delimitado por un anillo de distinta coloración; la púrpura; y los hematomas, por presión o traumas ${ }^{53}$.

Otras pistas para el diagnóstico se encuentran en la entrevista con el paciente que, por lo general, se presenta con inquietud, temblor fino de los músculos fa- ciales, ojos llorosos o, por el contrario, con "cara de jugador de póquer”. El interés del paciente en su lesión, la tendencia a exhibirla y a estar enfadado, pueden levantar sospecha de autoagresión; es frecuente que exponga historias sin contenido o inconsistentes y que exhiba la llamada "profecía melodramática", la cual le permite contestar preguntas del médico acerca de dónde será la próxima lesión o cómo será su aspecto ${ }^{53}$.

El dermatólogo que sospeche una dermatitis artefacta debe descartar otras enfermedades diferentes, reduciendo al máximo el uso de pruebas o procedimientos. Estos pacientes cambian frecuentemente de médico, especialmente, cuando sienten que el tratante sospecha o hace retención de tratamientos. Típicamente, busca intervenciones invasivas con múltiples profesionales, con frecuente asistencia a las salas de urgencia, lo cual genera un gran riesgo de morbilidad significativa (infección, incapacidad, desfiguración, etc.) como resultado del esfuerzo sincero del personal asistencial de esclarecer la condición ${ }^{54}$.

La relación de las lesiones con los episodios de sonambulismo, la mejoría del cuadro clínico después de 
FIGURA 5. Dermatitis artefacta: lesión única autoinducida, con eccema y fisuras (cortesía de la doctora Victoria Franco).

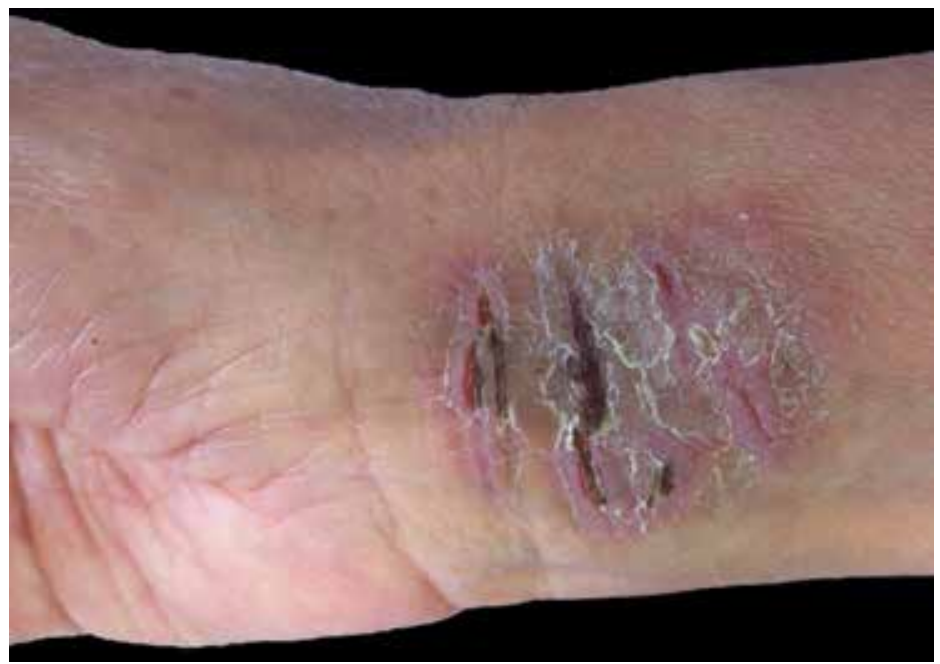

varias visitas, la aparición del cuadro en determinadas fechas, la reaparición con un nuevo empleo, el cambio de domicilio o colegio, la muerte de un familiar o cualquier otra situación que genere estrés emocional, son intentos de comunicación no verbal ${ }^{53}$.

Siempre que sea posible, debe practicarse una biopsia para el estudio histológico, ya que en muchas ocasiones es fundamental para el diagnóstico, sobre todo en aquellos casos que fácilmente se confunden con una dermatosis primaria ${ }^{54}$.

La dermatitis artefacta es probablemente uno de los problemas terapéuticos más complejos que existen en dermatología ${ }^{53}$. El tratamiento se fundamenta en cuatro pilares: I) establecer una compenetración terapéutica con el paciente; II) reestructurar la personalidad; III) adoptar medidas dermatológicas específicas, y IV) brindar tratamiento psiquiátrico.

Estos pacientes tienen dificultad para tolerar ciertas emociones, por lo que la confrontación directa sobre la producción de estos síntomas, raramente funciona. Con una fuerte alianza, la validación del sufrimiento de las experiencias del paciente y la exploración de los factores psicológicos de estrés, pueden ser de suma utilidad. Siempre es mejor adoptar una aproximación de apoyo y no una de condena. El dermatólogo debe estar preparado para iniciar un tratamiento prolongado, aceptando los empeoramientos repetidos, sin mostrar en ningún momento sentimientos hostiles por estos fracasos.

Las lesiones cutáneas se pueden curar con vendajes oclusivos. La rápida curación de una úlcera que antes se había mostrado rebelde a todas las terapéuticas, tiene gran valor diagnóstico, al igual que lo tiene el que aparezcan lesiones en lugares no vendados y que en la mayoría de los casos no se habían afectado previamente. Como los vendajes oclusivos pueden ser traspasados por objetos punzantes y permiten que se inyecten sustancias a través de ellos, puede interponerse una hoja de papel metálico entre la piel y el vendaje en la que quedarían grabadas las posibles manipulaciones ${ }^{53}$.

Aunque el paciente es resistente a la remisión al psiquiatra, el manejo debe incluir una solicitud sutil para la valoración por esta especialidad ${ }^{54}$. El tratamiento psiquiátrico incluye la combinación de tratamiento farmacológico y terapia comportamental. Los medicamentos psicotrópicos pueden dirigirse hacia la depresión y la ansiedad que frecuentemente acompañan la dermatitis artefacta. Los inhibidores selectivos de la recaptación de serotonina, como fluoxetina, sertralina, paroxetina y fluvoxamina, en altas dosis, se consideran la primera línea de tratamiento para los comportamientos compulsivos y autoagresivos. Los ansiolíticos, como la buspirona y las benzodiacepinas, pueden prescribirse si la ansiedad tiene un patrón dominante. Los antipsicóticos atípicos, como pimozida, olanzapina o risperidona, pueden ser útiles al tratar comportamientos autoagresivos y se usan solos o en combinación con uno de dichos inhibidores de la serotonina ${ }^{36,51}$.

\section{Dermatitis para-artefacta}

Es un trastorno del control de impulsos, en el cual hay una manipulación de una dermatosis específica pre- 


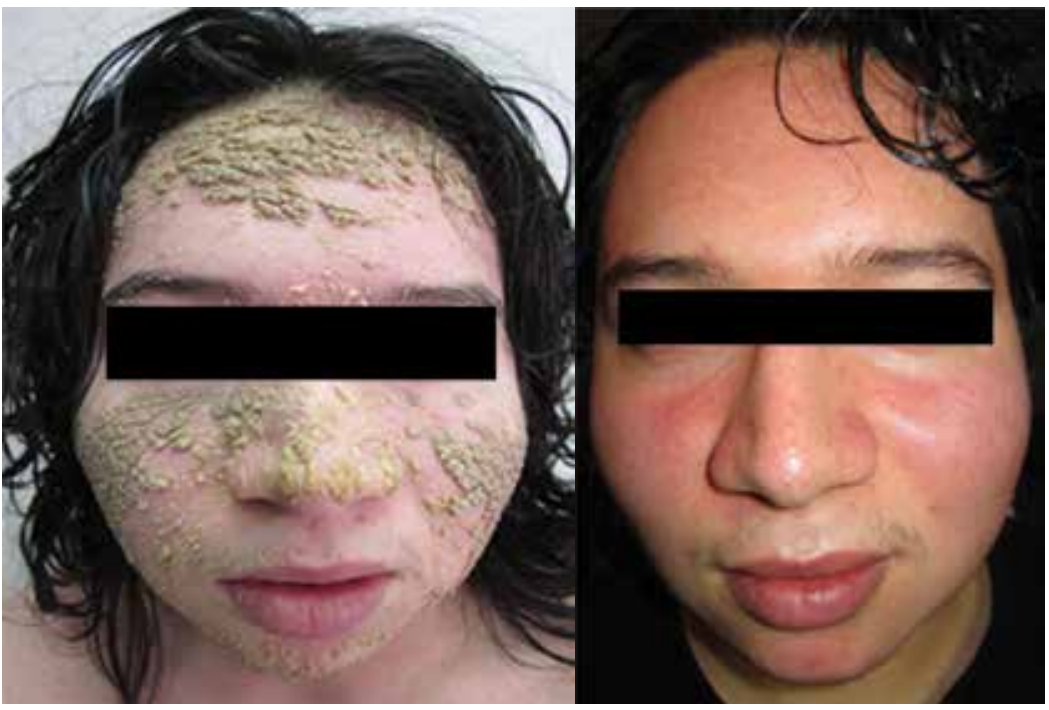

FigURA 6. Dermatosis neglecta: a) placas verrugosas en el rostro, b) aspecto posterior al aseo de las zonas afectadas (reproducida con autorización del Boletín Dermatológico CDFLLA. 2012;10:4-7) $)^{52}$. existente, aumentando la morbilidad. Por lo general, el paciente es semiconsciente y admite la autoagresión ${ }^{4}$.

\section{Dermatitis simulata}

Consiste en el uso de disfraces externos para simular una enfermedad sin que haya un daño real de la piel. Por lo general, se usa maquillaje para simular una erupción y tintes de impresión, para producir sudor de colores ${ }^{4}$.

\section{Dermatosis neglecta}

Conocida también como dermatitis passivata ${ }^{55}$, se caracteriza por la acumulación de queratina sobre la cara, el pecho, la espalda u otro sitio corporal, creando una capa gruesa de restos tegumentarios. Ocurre especialmente en pacientes paranoides, con trastornos del ánimo o con demencia frontotemporal ${ }^{4}$ (FIGURA 6). Su principal diagnóstico diferencial es la dermatosis terra firma forme.

\section{Trastorno por simulación}

Consiste en la presencia de lesiones simuladas conscientemente y en la creación de enfermedades para obtener una ganancia secundaria, que puede ser un beneficio legal, financiero $u$ ocupacional ${ }^{49}$. Por lo general, comprende un daño por presión, frote, corte, aplicación de sustancias químicas sobre la piel o infecciones autoinducidas, que generan trastornos en la curación de las heridas, cortaduras, mutilaciones, o quemaduras físicas o químicas. Es frecuente que se den en el contexto de las evaluaciones oficiales de enfermedades profesionales o de reclamaciones de seguros ${ }^{48}$.

\section{FORMAS ESPECIALES}

\section{Síndrome de Gardner-Diamond}

También conocido como púrpura psicógena, síndrome equimótico doloroso, síndrome de moretones dolorosos o síndrome de sensibilización autoeritrocitaria, es una rara reacción cutánea localizada y distintiva, que afecta preferentemente a mujeres adultas con alteraciones psicológicas. El mecanismo exacto de este síndrome no es bien entendido. Los episodios se caracterizan por estados de pródromos con prurito o con sensación de quemadura; posteriormente, aparecen máculas azules dolorosas seguidas por placas eritemato-edematosas y lesiones equimóticas que sanan en una a dos semanas, sin dejar defectos residuales. Por lo general, compromete las extremidades, más frecuentemente las piernas. Los pacientes pueden presentar otros síntomas, como dolor abdominal, náuseas, vómito, dolor articular, dolor de cabeza y hemorragias, como epistaxis o hemorragia gastrointestinal ${ }^{56}$.

\section{Síndrome de Münchhausen}

Se caracteriza por la presencia de pseudología fantás- 


\section{"El reconocimiento y el manejo de los pacientes con alguna de las psicodermatosis primarias, no es una tarea sencilla, pero su desconocimiento puede retrasar los diagnósticos y empeorar el pronóstico de la enfermedad".}

tica, múltiples visitas a diferentes médicos y autoagresión. Es típico que se refieran numerosas hospitalizaciones y cirugías, algunas veces con cicatrices visibles. Los pacientes se quejan de síntomas con descripciones dramáticas e información falsa en su historia médica. Frecuentemente, se asocia a una manía subyacente o un trastorno grave de la personalidad, como la personalidad antisocial o el trastorno límite ${ }^{48,49}$.

\section{Síndrome de Münchhausen por poder}

Se presenta principalmente en niños que son lesionados por sus cuidadores, con el objetivo de establecer contacto con el personal de salud. Es una forma de maltrato y abuso infantil, que debe notificarse a las autoridades competentes ${ }^{48,49}$.

\section{Prurito psicógeno}

El prurito se define como una sensación desagradable que conlleva rascado y que representa sufrimiento. El prurito psicógeno es una entidad en la que existe una sensación imperiosa de rascar la piel, sin una enfermedad física o dermatológica de base ${ }^{4}$.

En varios estudios se han descrito las áreas afectivas, motoras y sensoriales que son activadas en el cerebro cuando ocurre el prurito, por lo que se puede afirmar que es una sensación que se acompaña de la activación contralateral del córtex anterior y por la activación ipsilateral de las áreas motoras suplementarias en el lóbulo parietal inferior. La demostración del papel del cerebro en la patogénesis de esta condición, confirma la existencia de un componente psicológico en cada caso de prurito ${ }^{57,58}$.

En el prurito psicógeno los episodios son imprede- cibles, con un comienzo y una terminación abruptos, que acontecen especialmente durante el tiempo de relajación. Los sitios más comúnmente afectados son las piernas, los brazos, la espalda y los genitales (prurito anogenital). Puede haber asociación con cuadros clínicos de ansiedad o depresión o pueden ser precedidos por episodios de estrés psicológico ${ }^{30,59}$. El prurito psicógeno es un diagnóstico de exclusión; después de descartar causas sistémicas o cutáneas, y según otras alteraciones psicológicas de base, puede iniciarse el tratamiento con antidepresivos tricíclicos con efecto antihistamínico, como la doxepina ${ }^{30}$.

\section{TRASTORNOS SENSORIALES CUTÁNEOS}

\section{Glosodinia, vulvodinia, escrotodinia, anodinia}

Cuando un paciente se presenta con una sensación desagradable en la piel, como prurito, sensación de ardor o escozor, siempre debe excluirse una causa orgánica (por ejemplo, neuropatía periférica). Por consiguiente, estos pacientes requieren una evaluación neurológica, para garantizar que esta condición no requiera tratamiento, como por diabetes mellitus. Asumiendo que no hay una condición médica diagnosticable y que el paciente realmente padezca de estos síntomas, se deben examinar y tratar las condiciones psiquiátricas concomitantes, como depresión o ansiedad, lo que mejorará significativamente la sensación cutánea anormal. Si no hay una causa reconocible, pueden usarse empíricamente antihistamínicos o antidepresivos tricíclicos, por sus efectos antipruriginosos y analgésicos ${ }^{10}$. 


\section{CONCLUSIONES}

El reconocimiento y el manejo de los pacientes con alguna de las psicodermatosis primarias, no es una tarea sencilla, pero su desconocimiento puede retrasar los diagnósticos y empeorar el pronóstico de la enfermedad. Es por esto que la educación en este campo y el entrenamiento para la adquisición de ciertas habilidades en la entrevista médica, son de suma importancia para lograr empatía con el paciente y comandar las estrategias terapéuticas que mejor se ajusten al individuo. Siempre se debe tener en cuenta que, en la gran mayoría de estos trastornos, puede existir una mala introspección, con pobre reacción al tratamiento y frecuentes recaídas, lo que los convierte en frustrantes para el médico, el paciente y su familia.

Si bien el dermatólogo debe estar entrenado para manejar estas condiciones, es importante la atención integral y el apoyo multidisciplinario de otras especialidades, como psiquiatría, psicología y medicina familiar, para poder abordar al paciente en su contexto biopsicosocial, con el único objetivo de mejorar su funcionalidad y su calidad de vida.

Finalmente, cabe resaltar que, aunque el interés y el estudio de la psicodermatología han aumentado en las últimas décadas, los vacíos del conocimiento respecto a la fisiopatología, la epidemiología y la efectividad de los tratamientos, siguen siendo enormes y requieren del compromiso de la comunidad científica para brindar mejores opciones terapéuticas en el futuro.

\section{REFERENCIAS}

1. França K, Chacón A, Ledon J, Savas J, Nouri K. Pyschodermatology: A trip through history. An Bras Dermatol. 2013;88:842-3.

2. Jafferany M, Stoep Vander A, Dumitrescu A, Hornung RL. The knowledge, awareness, and practice patterns of dermatologists toward psychocutaneous disorders: Results of a survey study. Int J Dermatol. 2010;49:784-9.

3. Basavaraj KH, Navya MA, Rashmi R. Relevance of psychiatry in dermatology: Present concepts. Indian J Psychiatry. 2010;52:270-5.

4. Yadav S, Narang T, Kumaran MS. Psychodermatology: A comprehensive review. Indian J Dermatol Venereol Leprol. 2013;79:176-92.

5. Blancas F. Dermatología integral. Dermatología Rev Mex. 2005;49:193-5.

6. O’Sullivan RL, Lipper G, Lerner EA. The neuro-immuno-cutaneous-endocrine network: Relationship of mind and skin. Arch Dermatol. 1998;134:1431-5.

7. Brazzini B, Ghersetich I, Hercogova J, Lotti T. The neuro-immuno-cutaneous-endocrine network: Relationship between mind and skin. Dermatol Ther. 2003;16:123-31.
8. Arck PC, Slominski A, Theoharides TC, Peters EMJ, Paus R. Neuroimmunology of stress: Skin takes center stage. J Invest Dermatol. 2006;126:1697-704.

9. Locala JA. Current concepts in psychodermatology. Curr Psychiatry Rep. 2009;11:211-8.

10. Leon A, Levin E, Koo J. Psychodermatology: An overview. Semin Cutan Med Surg. 2013;32:64-7.

11. Software - historias clínicas Dynamica Gerencial ${ }^{\circledR}$, Departamento de Sistemas, Centro Dermatológico Federico Lleras Acosta, 2016.

12. Freudenmann RW, Lepping P. Delusional infestation. Clin Microbiol Rev. 2009;22:690-732.

13. Heller MM, Wong JW, Lee ES, Ladizinski B, Grau M, Howard JL, et al. Delusional infestations: Clinical presentation, diagnosis and treatment. Int J Dermatol. 2013;52:775-83.

14. Lepping P, Freudenmann RW. Delusional parasitosis: A new pathway for diagnosis and treatment. Clin Exp Dermatol. 2008;33:113-7.

15. Ahmed A, Bewley A. Delusional infestation and patient adherence to treatment: An observational study. Br J Dermatol. 2013;169:607-10.

16. Lee CS. Delusions of parasitosis. Dermatol Ther. 2008;21:2-7.

17. Zomer SF, De Wit RFE, van Bronswijk JEHM, Nabarro G, van Vloten WA. Delusions of parasitosis. A psychiatric disorder to be treated by dermatologists? An analysis of 33 patients. $\mathrm{Br} J$ Dermatol. 1998;138:1030-2.

18. Bhatia MS, Jhanjee A, Srivastava S. Delusional infestation: A clinical profile. Asian J Psychiatr. 2013;6:124-7.

19. Middelveen MJ, Mayne PJ, Kahn DG, Stricker RB. Characterization and evolution of dermal filaments from patients with Morgellons disease. Clin Cosmet Investig Dermatol. 2013;6:1-21.

20. Pearson ML, Selby JV, Katz KA, Cantrell V, Braden CR, Parise $\mathrm{ME}$, et al. Clinical, epidemiologic, histopathologic and molecular features of an unexplained dermopathy. PLoS One. 2012;7:e29908.

21. Trabert W. 100 years of delusional parasitosis. Meta-analysis of 1,223 case reports. Psychopathology. 1995;28:238-46.

22. Muñoz H, Bayona L. Síndrome de Ekbom: a propósito de un caso. Rev Colomb Psiquiat. 2014;4:61-5.

23. Hylwa SA, Bury JE, Davis MDP, Pittelkow M, Bostwick JM. Delusional infestation, including delusions of parasitosis: Results of histologic examination of skin biopsy and patientprovided skin specimens. Arch Dermatol. 2011;147:1041-5.

24. Rodríguez-Cerdeira C, Pera JT, Arenas R. El síndrome de Ekbom: un trastorno entre la dermatología y la psiquiatría. Rev Colomb Psiquiat. 2010;39:440-

25. Ladizinski B, Elpern DJ. Dermoscopy in delusions of parasitosis. Int J Dermatol. 2013;52:838-9.

26. Wong JW, Koo JYM. Psychopharmacological therapies in dermatology. Dermatol Online J. 2013;19:1-19.

27. Gupta MA, Gupta AK. Current concepts in psychodermatology. Curr Psychiatry Rep. 2014;16:449.

28. Mufaddel A, Osman OT, Almugaddam F, Jafferany M. A review of body dysmorphic disorder and its presentation in different clinical settings. Prim Care Companion CNS Disord. 2013;15:12r01464.

29. American Psychiatric Association. Diagnostic and Statistical Manual of Mental Disorders. 5th edition. Arlington: American Psychiatric Association; 2014. 
30. Ghosh S, Behere R, Sharma P, Savitha S. Relevant issues in pharmacotherapy of psycho-cutaneous disorders. Indian J Dermatol. 2013;58:61-4.

31. Ipser J, Sander C, Stein D. Pharmacotherapy and psychotherapy for body dysmorphic disorder. Cochrane Database Syst Rev. 2009;21.

32. Shoenfeld N, Rosenberg O, Kotler M, Dannon PN. Tricotillomania: Pathopsychology theories and treatment possibilities. Isr Med Assoc J. 2012;14:125-9.

33. Franklin ME, Zagrabbe K, Benavides KL. Trichotillomania and its treatment: A review and recommendations. Expert Rev Neurother. 2011;11:1165-74.

34. Harrison JP, Franklin ME. Pediatric trichotillomania. Curr Psychiatry Rep. 2012;14:188-96.

35. Snorrason I, Berlin G, Lee H. Optimizing psychological interventions for trichotillomania (hair-pulling disorder): An update on current empirical status. Psychol Res Behav Manag. 2015;8:105-13.

36. Wong JW, Nguyen T V, Koo JY. Primary psychiatric conditions: Dermatitis artefacta, trichotillomania and neurotic excoriations. Indian J Dermatol. 2013;58:44-8.

37. Ospina J, Jose VJ. Síndrome de Rapunzel reporte de caso y revisión de la literatura. Rev Col Gastroenterol. 2011;26:30-3.

38. Walsh KH, Mcdougle CJ. Trichotillomania. Presentation, etiology, diagnosis and therapy. Am J Clin Derm. 2001;2:327-33.

39. Rakowska A, Slowinska M, Olszewska M, Rudnicka L. New trichoscopy findings in trichotillomania: Flame hairs, V-sign, hook hairs, hair powder, tulip hairs. Acta Derm Venereol. 2014;94:303-6.

40. Jain N, Doshi B, Khopkar U. Trichoscopy in alopecias: Diagnosis simplified. Int J Trichology. 2013;5:170-8.

41. Elston DM. What's new in the histologic evaluation of alopecia and hair-related disorders?. Dermatol Clin. 2012;30:685-94.

42. Lachapelle JM, Pierard GE. Traumatic alopecia in trichotillomania: A pathogenic interpretation of histologic lesions in the pilosebaceous unit. J Cutan Pathol. 1977;4:51-67.

43. Bergfeld W, Mulinari-Brenner F, McCarron K, Embi C. The combined utilization of clinical and histological findings in the diagnosis of trichotillomania. J Cutan Pathol. 2002;29:207-14.

44. Starcevic V. Trichotillomania: Impulsive, compulsive or both? Aust N Z J Psychiatry. 2015;49:660-1.

45. Rozenman M, Peris TS, González A, Piacentini J. Clinical characteristics of pediatric trichotillomania: Comparisons with obsessive-compulsive and tic disorders. Child Psychiatry Hum Dev. 2016;47:124-32.

46. Rothbart R, Stein DJ. Pharmacotherapy of trichotillomania (hair pulling disorder): An updated systematic review. Expert Opin Pharmacother. 2014;15:2709-19.

47. Rothbart R, Amos T, Siegfried N, Ipser J, Fineberg N, Chamberlain S, et al. Pharmacotherapy for trichotillomania. Cochrane Rev. 2013;11:CDoo7662.

48. Harth W, Taube KM, Gieler U. Facticious disorders in dermatology. J Dtsch Dermatol Ges. 2010;8:361-74.

49. Gieler U, Consoli SG, Tomas-Aragones L, Linder DM, Jemec GBE, Poot F, et al. Self-inflicted lesions in dermatology: Terminology and classification - A position paper from the European Society for Dermatology and Psychiatry (ESDaP). Acta Derm Venereol. 2013;93:4-12.
50. Misery L, Chastaing M, Touboul S, Callot V, Schollhammer $\mathrm{M}$, Young P, et al. Psychogenic skin excoriations: Diagnostic criteria, semiological analysis and psychiatric profiles. Acta Derm Venereol. 2012;92:416-8.

51. Koblenzer CS, Gupta R. Neurotic excoriations and dermatitis artefacta. Semin Cutan Med Surg. 2013;32:95-10o.

52. Shah KN, Fried RG. Factitial dermatoses in children. Curr Opin Pediatr. 2006;18:403-9.

53. Rodríguez A, García B. Dermatitis artefacta: revisión. Actas Dermosifiliogr. 2013;104:854-66.

54. Gordon-Elliott JS, Muskin PR. Managing the patient with psychiatric issues in dermatologic practice. Clin Dermatol. 2013;31:3-10.

55. Tovar A, Solórzano A. Dermatosis neglecta (dermatitis passivata). Bol Dermatol. 2012;10:4-7.

56. Ghosh S, Bandyopadhyay D, Nath S, Sarkar S. Psychogenic purpura. Indian J Psychiatry. 2013;55:192.

57. Misery L, Alexandre S, Dutray S, Chastaing M, Consoli SG, Audra $\mathrm{H}$, et al. Functional itch disorder or psychogenic pruritus: Suggested diagnosis criteria from the French Psychodermatology Group. Acta Derm Venereol. 2007;87:341-4.

58. Misery L, Wallengren J, Weisshaar E, Zalewska A. Validation of diagnosis criteria of functional itch disorder or psychogenic pruritus. Acta Derm Venereol. 2008;88:503-4.

59. Solórzano-Amador A, Ronderos-Acevedo MC. Prurito. Parte I. Fisiopatología y enfermedades asociadas. Rev CES Med. 2012;26:249-59. 